\title{
Social Media - A revolution in Indian society
}

\author{
Medatwal Toshi ${ }^{1}$ and Dr. Jain Pooja ${ }^{2}$ \\ ${ }^{1}$ Scholar, BFA- Applied Art, School of Planning and Design, Manipal University Jaipur, Rajasthan, India \\ ${ }^{2}$ Assistant Professor, Department of Fine Arts, Manipal University Jaipur, Rajasthan, India
}

\begin{abstract}
Background/Objectives: Advertising is a procedure and a non-personal communication where a message is a curriculum to publicize a product, service or an idea by an identified sponsor. Its technology that has played a major role in turning the face of traditional advertising to the new media. Methods/Statistical analysis: Social media is computer medicated technology that assists in creation as well as the sharing of information through virtual networks. Furthermore, social media has had a tremendous impact on our life's, not only by revolutionizing the way of communication and socialization but also by making it more utilitarian, expanded, nimble and technical. Findings: Social media websites became a massive part of our society, as in our daily routine from waking up to being asleep we are connected to social media networks. Social media became voice of the advertisers that personalized the brand and aided them in extending the messages wherever they want. Improvements/Applications: Eventually, it became one of the most accessible, inexpensive, and adequate modes of gaining exposure and strengthen the business.
\end{abstract}

\section{Index Terms}

Advertising, Modernization, Social Media, Society, Technology

\footnotetext{
Corresponding author : Medatwal Toshi

Toshi.medatwal222@gmail.com

- Manuscript received May 1, 2018.

- Revised May 18, 2018; Accepted June 2, 2018.

- Date of publication June 30, 2018.

(c) The Academic Society of Convergence Science Inc.

2546-1583 @ 2017 IJEMR. Personal use is permitted, but republication/redistribution requires IJEMR permission.
} 


\section{I.INTRODUCTION}

Advertising is a procedure where a message is programmed to publicize a product, service or an idea among the targeted audience. This is a nonpersonal communication whose major task is to instruct, persuade, and anamnesis about the product and a paid form done by the identified sponsors having full control of marketers on it. Initially, during the pre-industrial age, advertising initiated with mouth to mouth marketing. At that time public criers used to proclaim sale article and interesting news to the people by using vivid symbols and visuals. In early printing, one of the gigantic contraptions in the evolution of advertising was the printing press that was a step towards the civilization. With the origin of newspaper advertising, the procedure of advertising thoroughly changed. Therefore, Merchants, manufacturers, vendors started using newspaper to advertise themselves, so that they could cross the boundaries.

Period of Expansion evokes with the Industrial revolution that commutated the life's as well as the lifestyle of people. Now goods started generating faster, hence the competition started to flare up. Technology has a big hand in the introduction of digital advertising. It introduced billboards, television, radio, mobile devices, social networks and most importantly internet which aided advertisers to create the advertising process for a digital media [1]

Technology is considered as the mixture of technical skills, approaches, and actions used in the production of goods and scientific analysis. With technology People started working in a very accessible way, now they can communicate with family and friends at any place by doing phone calls, or swap information online through digital media. Whether it's a commercial or personal, all kind of works are dependent on technology. With the growth in competition in the market, marketers realized the better use of technology through advertising [2].

\section{A. Technologies that changed Advertising and our lives}

1. Email: Electronic Mail is a way of exchanging messages between people using electronic devices, and is recognized as the first widely published mode of digital advertising.

2. Phone call: Helps people to do conversation with each other by being at different places. It helps marketers to contact their target audience to maintain good relations taking feedbacks from them.

3. Texting: It's a way of sending electronic messages between two or more users of a mobile phone, provided direct connection to the target audience.

4. Instant Messaging: Is a way of exchanging the messages through the internet or cellular application. This provided a platform to the marketers to communicate and spread words for the benefit of the business.

5. Social Networking: Provides a platform where one can be connected with their friends and family and can do promotional works as well.

6. Tweeting: Twitter allows broadcast short messages called "tweets" to people who have elected to follow your posts. It gave a space to the small scale business to get updated in the market and following the market trends by using trending hashtags.

7. Blogs: Blogs are written documental posts, posted on some internet sites. They can be commercial based or personal.

8. Video Conferencing: It provides face-toface meeting without having to be at the same place. [3]

Throughout history, advancement in technology leads a major role in how individuals are exposed to new information, From printing to new media to the internet, the deviation and preferment in technology aided marketers as well as people a lot, both of them got benefits in communication as well as in publication. [4]

\section{II.SOCIAL MEDIA}

It is the aggregate of online communications channels that are committed to content sharing, interaction, collaboration on society based input.

- Social media are interactive, hence, is the lifeblood of the social media organism. 
- Are UGC (user generated content) such as texting posts or comments, photos through online Interaction

The indulgence of social media is affiliated with users through web-based technologies like computers, mobile devices etc. Social media have commutated the way of communication between individuals and large organizations. Social media is not like paper-based media (magazines and newspapers) and traditional electronic media (TV), whereas it has one source of transmission to many receivers, such as a newspaper and radio station. Popular social media websites are Google+, Instagram, LinkedIn, Pinterest, Snapchat, Twitter, WhatsApp, and YouTube [5].

\section{A. Types of Social Media}

1. Social Networking: Social networks assist people, and organizations connect online to share information, ideas and messages.

Benefits: Helps in market research, extending brand awareness, building relationship, giving services to customers etc.

Example: Facebook; The viral of Facebook is spreading so rapidly in our country that each and every person is using it continuously, whether it's an aged person or a teenager everyone uses Facebook on a regular basis.

2. Discussion Forum: Discussion forums are the primeval category of social media that provides a platform to interrogate questions and enlighten the trending updates and views of people whom they are following Benefits: people can do deliberation on their interest affair with the people having good knowledge of that.

Examples: Reddit; Got so much popularity in society as it provides a podium where people can do interaction on their significant topic and get updated.

3. E-Commerce: Are used to spot trends, follow brands, and to make purchases. It merged the social experience with the buying experience.

Benefits: Brands can build awareness, goodwill, and sell products via new channels.

Example: Amazon; Known as the big mart of the internet, Amazon is the site where one can find everything to purchase. The growth in online shopping is increasing so fast that whatever people want to buy they firstly check it online.

4. Economy Sharing Networks: This network associate people online for the purpose of acquisition, share, buy, sell and trade products and services.

Benefits: It made life easier by providing option share money and other transactions by seating at their home.

Example: Paytm; Nothing perhaps more rapidly eminent like Paytm, it got so much habitude at the time of demonetization. As formerly each and every single person was using Paytm, whether it's an auto driver or a café.

5. Interactive Networks: By these networks, people can interact with their friends, families, loved one by using mobile phone and any other gadget by sitting at home or any other place.

Benefits: These networks made peoples life so easy that now they don't need to go anywhere to contact anyone.

Example: WhatsApp; it reciprocate the way of interaction between people because of its easily assessed and usability.

6. Video Sites: On such kind of sites one can see an already recorded or uploaded video anywhere, that can be entertaining as well as educational or funny and non- fictional, TV and web series etc.

Benefits: provides a dais where one can view likewise upload the videos of their concern.

Example: YouTube; YouTube is the first site for video assessing. Moreover became the most popular social networking medium. [6]

\section{B. How Social Media has interwoven with society}

Initially, social media does not have any reach to the rural areas of our country. But thanks to reliance Jio, that provided internet access to our country that too at economic friendly offers, this thing open up the doors of technology. Now people from every corner of the country can be connected, marketers can reach rural India easily and can target them as well, news and information can be shared easily to each and every part of the country.

From the day of the invention of social media it is being used for the betterment of society, for making peoples life accessible, commutable, affiliated and agile, gradually as the users of social media were increasing, new techniques and applicability arose in 
this network. Soon after the invention of social networking sites, social media come up with sites that provide a platform where one can trade, view and upload videos, pay bills, order food, book hotels or resorts, do transactions, book cabs, rent a house, get an education, matrimonial sites etc. In today's time, social media is ruling the world because of its easy access and usability. And this thing made society so habitual to it, that they use it for doing their every small work. Society is at that stage that they want works to be done in a fast and easier way without many efforts, and social media has provided them that place where they just have to click and the work is done, and this is the reason that made social media so popular. [7]

Our society has some specific groups that are, societal, political, and economical, and all of these groups are accessing social media for their enrichment in both personal and working life. As social media is a way of connection between people, it is connecting $80 \%$ of our society, and giving leverage to them, it has connected our society by breaking all the boundaries of cast, color, religion, and distance, it helped to re-connect people with their old fellows and contacts, and also in making new friends, sharing content and pictures, trade ideas, and in many more activities. For people who lives are away from their families, its social media that helps them to spent time with their family online, with this they are able to recreate the sense of the proximity of living together in the same home. Likewise, politics is also interwoven with society, social media is a good source of knowledge and news. People use social media to get days top news whether on social networking sites or through apps. What else can be better than this to the politicians where they can get instant publicity along with viewer's comments and feedback, this also helps the parties to be in touch with the society, Social networking helps in marinating fundamentally rewire human society, allowing people to communicate with one another more openly, and helping social organizations persuade among oncemarginalized groups. Social media helps the politician parities to directly reach society and collectively share their promises and ideas to scale of different sizes of an audience [8].

Social Media is an effective mean of communication whose occupancy is very inexpensive and aids a brand to enhance its image, popularity, loyalty and updating the market. By this, marketers can enthuse consumers to visit their website by showcasing them some offers or sales, this thing cannot be done in any other mode of marketing. It also helps in getting feedbacks and other instructions from their customers in understanding the market, and finetune their products and strategies. The most wonderful invention of social media is e-commerce sites, that granted a platform where people can buy and sell things, this derived in saving time and money, as these sites provide lot many offers, vouchers, sales as well as cash backs, and not only this, it also offers free delivery that too at Cash on delivery, which became so convenient for buyers. However, social media not only abated our economy in trading only but also catered mode of money transaction, it's this invention changed the economy acutely, now society started using social media sites for money exchange that too in a safe and quick way.

Conversely, it gave benefits to students and designers as well, by equipping a space where they can show off their portfolios and flaunt their work for inspiration and promotion as well. Example: Behance and Pinterest. It's not just enough, social media is so forward that one can get news on it prior to anyone, one can be amended anytime, anywhere, by reading as well as watching the live telecast. Eventually, social media brings those sites where one can apply for the job and can get updates for job requirements as well. This invention not only aided people but also our economy in catering option for applying and hiring of jobs. If all works started being on social media then how matrimonial and matchmaking sites be back, gradually it started helping our society in maintaining the traditional rituals of arranged marriages, and aiding them in finding their perfect match. If every work can be done on social media then why not study, social media served educational sites through which students and learners can do the study of the subject that they want. These sites consist of tutorials videos explain the facts and figures, this leads to development in our society, as now those students who cannot afford higher studies can also study at home [9].

Indeed, this thing can be well said that social media has interwoven with our society, and linked with it in various aspect, from smallest to largest all kind of works and services can be assessed through it. It is benefiting our society from the perspective of a common man to a student to a marketer.

\section{Role of Social media in Advertising}

The introduction of social media not only changed the procedure of communication but also changed the procedure of advertising. Initially, social media begin as an approach of connection between people, and gradually became a mode of advertising as well. Moreover, marketers realized that they should drive wherever their clients are, and this constituted raise in the social media advertising. Its development shifted the old traditional method of advertising to 
the new media. Social media contrived advertising much easier as now advertisers can advertise their products and services on a habitual as well as accessible way without spending much amount [10].

Social media gave a contingency to the marketers to get their targets analysis on the sites, as it requires personal information of an individual, their age, gender, interests, and locations as well, that avails the advertisers in devising specific target groups and categorizing their advertisements. Social media accorded advantages to both the advertiser as well as the users, for advertisers it precisely reaches the people who are interested in the product or service, conversely for users, they can only regard those ads and products that appeals them [11]. Social media not only bear back the buyers to the brand but also creates its fidelity. Its fact that social media can be used in a diversified form as it can be used with the suitable interest of the users, needs of the business and society [12].

\section{III.RESEARCH METHODOLOGY}

The research type was based on a quantitative basis and collected 203 samples from the areas nearby Jaipur city in Rajasthan, India. The samples are of different occupations from age above 16 of all genders. The tool for data collection was a questionnaire.

The process of data collection shown positive results of the research and concluded the results as shown in further figures.

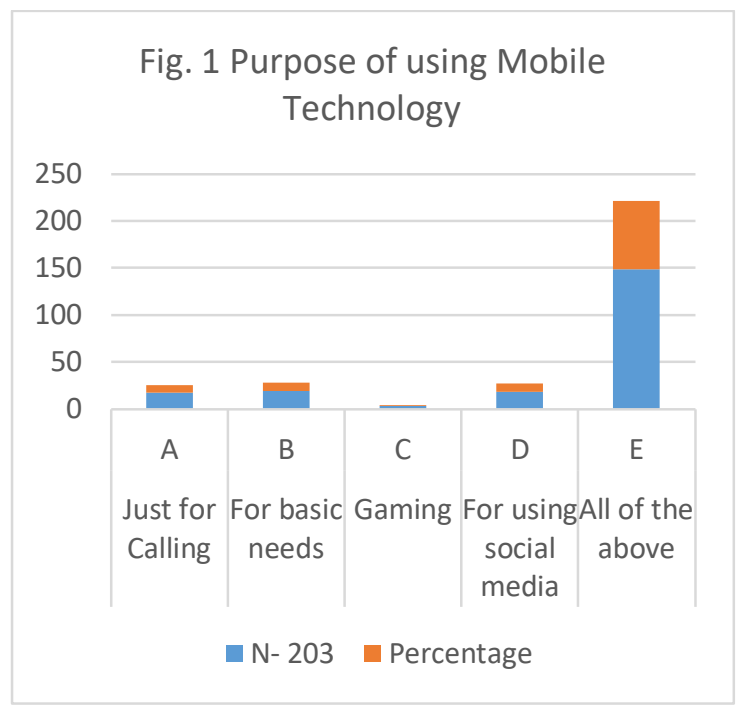

Fig.1. Purpose of using Mobile Technology
Fig. 1 showing that how people are using social media for their daily use, for every small work they are using social media, hence it can be well said that it became part of their lifestyle.

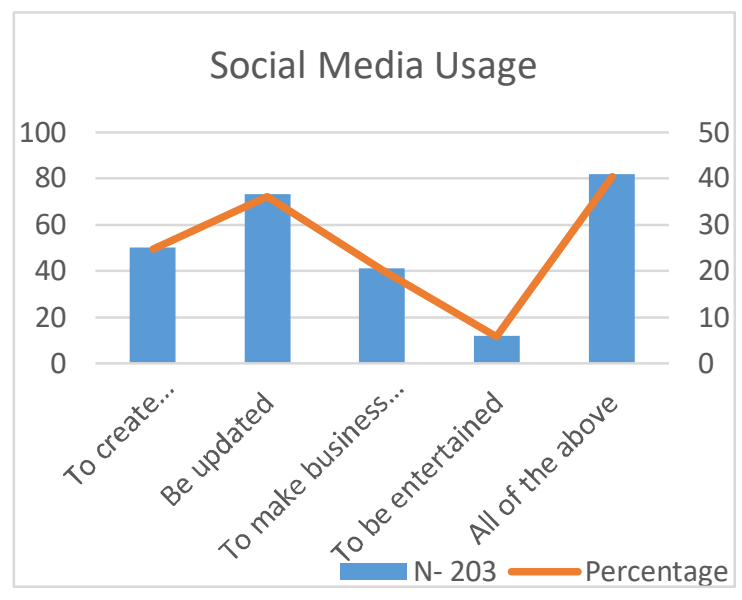

Fig. 2. Social Media usage in Indian society

Fig. 2 shows the results of the usage of social media in society, that it's not only helping us in our daily life usages only but also in making our life easier, entertained and connected.

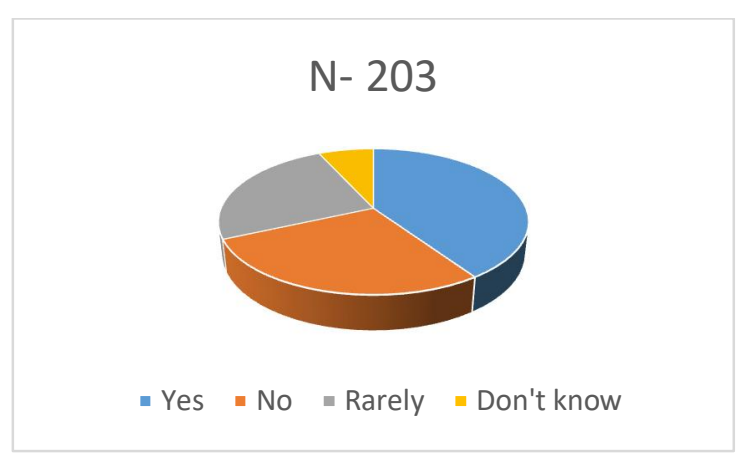

Fig. 3. Social Media advertisements are effective

Fig. 3 results in the effectiveness of social media advertisement on society, people are more likely to see advertisements on social media rather than any other medium. Hence it can be said that social media ruled the world of advertising.

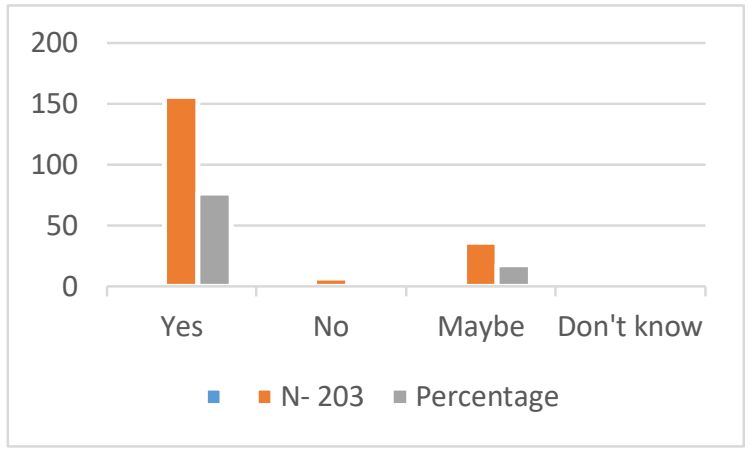

Fig. 4. Social Media is useful for our Society 
Fig. 4 is revealing the results of the usefulness of social media in our society. The results are totally positive with $77 \%$ of the population and show social media has a great impact on the society such that it became a very useful part of their life.

\section{IV.CONCLUSION}

This paper will help in identifying the practices of social media in personal and in commercial perspective, and how society is fluctuating towards social media for connections, to get news and knowledge about everything. This paper was showing that how technology has recouped the old traditional method of advertising with the new digital media. People use technology for doing their each and every work, whether it is reading book or watching movies, reading news or ordering food, doing shopping or placing advertisements every work is done on social media, and by providing all these services to us, social media not only made our life relaxed, debauched and technical but also helped in saving economy, as now the works for which people need to run can be done from home or any other place, this resulted in making our society more modular, smart and powerful. Indeed, social media have changed our lives and lifestyle and made life accessible, agile, progressive and modular as well.

\section{REFERENCES}

[1] S. N Murthy, U Bhujanna (2007), Advertising, New Delhi, Excel Books.413 (3-34)

[2] Mindi Orth, Technology and how we communicate, Chron. Retrieved http://smallbusiness.chron.com/technology-communicate27322.html 3

[3] Edosomwan Simeon, Prakasan Sitalaskshmi Kalangot, (July 2011). The History of Social Media and its Impact on Business, 79-91. Retrieved from https://www.researchgate.net/publication/303216233

[4] Curtis Foreman, type of Social Medias, Hootsuite. Retrieved from https://blog.hootsuite.com/types-of-socialmedia/

[5] Social Media and its impact essay, Bartleyby.com. Retrieved from https://www.bartleby.com/essay/SocialMedia-and-its-Impact-FKC6QSLYTJ

[6] Gregory Dean in Marketing Philosophy (09 Tuesday MAR 2010) Advertising - Then and Now. Retrieved from https://marketography.com

[7] Maryanne Gaitho (December 13, 2017) what is the real impact of social media? Retrieved from https://www.simplilearn.com/real-impact-social-mediaarticle

[8] Jenny Q. Ta (August 13, 2014) What Impact Has Social Media Truly Had On Society. Retrieved from https://www.business2community.com/socialmedia/impact-social-media-truly-society-0974685

[9] Mark W. Schaefer (4 November 2016) 15 Amazing ways social media is changing the world, https://www.businessesgrow.com
[10] Laura Lake (October 14, 2017) Understanding the Role of Social Media in Marketing. Retrieved from https://lauralake.com/test-post-6/

[11] MICHAEL COHN (2 September 2010), the Impact of Social Media on Advertising, Compukol Communication LLC.

[12] Manuel Gomez-Rodriguez, Krishna P. Gummadi, (26 Mar 2014) Quantifying Information Overload in Social Media and Its Impact on Social Contagions, Cornell University Library.

[13] Carlos M. Gutierrez, (Aug 31, 2017) technology has changed advertising forever. Retrieved from https://www.huffingtonpost.com

[14] Konrad Feldman (September 13th 2014), Special Report Advertising and Technology, The rise of an electronic marketplace for online ads is reshaping the media business, The Economist, 16(10-11). 